\title{
En torno a la hermenéutica blanca de Sery Tiempo en Edith Stein
}

\author{
JOSÉ LUIS CABALLERO BONO \\ Universidad Pontificia de Salamanca (España) \\ jlcaballerobo@upsa.es
}

\begin{abstract}
Resumen
Edith Stein leyó la obra de Martin Heidegger Sery tiempo en 1927, el mismo año de su publicación. Este artículo trata de reconstruir la «hermenéutica blanca» de esa lectura, es decir, las reacciones que pudo suscitar y que no fueron puestas por escrito en ese momento. Se toman como guía tres comentarios azarosos de la autora en relación tanto a Ser y tiempo como a la filosofía de Heidegger en general.
\end{abstract}

Palabras claves: Sein und Zeit, extrañeza, mala conciencia, teleología inmanente, temporalidad.

\section{Edith Stein and Heidegger's «Being and Time»: A White Hermeneutics}

\begin{abstract}
Edith Stein read Martin Heidegger's Being and Time in 1927, the year of its publication. This article explores a «white hermeneutics» of her reading, tracing some possible reactions to this work that Stein did not record at the time. Three incidental comments on Being and Time and Heidegger's philosophy in general made by Stein guide our research.
\end{abstract}

Key words: Sein und Zeit, Strangeness, Bad Conscience, Immanent Teleology, Transience.

Doctor en filosofía por la Universidad Complutense de Madrid. Licenciado en Estudios Eclesiásticos por la Universidad Pontificia Comillas. Entre sus publicaciones destacan el libro Edith Stein (1891-1942) (2001) y los artículos "Zubiri y Goldschmidt" (1999), "La evolución como emergentismo transcendental en Zubiri” (2000), "Edith Stein davanti alla prova anselmiana" (2001), "Sentido y alcance de la empatía en Edith Stein" (2002), "Notas sobre tradición y modernidad en la Dialectica resolutio de Alonso de la Veracruz" (2003), "Muerte y supervivencia en Julián Marías" (2006), "La empatía y su importancia en la vida del hombre" (2009), "Ejes transversales del pensamiento de Edith Stein" (2010), "Ser mirado y mirar. Apuntes para un simbolismo" (2011). Es asimismo editor de los Escritos teológicos y filosóficos de Augusto Andrés Ortega (20042010), traductor de Edith Stein al español y editor del libro Ocho filósofos españoles contemporáneos (2008). 


\section{Contexto de la relación con Heidegger}

Edith Stein conoció a Martin Heidegger una tarde de verano de 1916 en Friburgo de Brisgovia, en la casa de Edmund Husserl, durante los días previos al examen de doctorado al que había de presentarse en la Universidad Albert-Ludwig. De ese centro era Heidegger profesor asistente y su novia, Elfride Petri, una alumna. La primera impresión de Edith Stein fue favorable: «Aquella tarde me cayó muy bien Heidegger. Era silencioso y vuelto a sí cuando no se hablaba de filosofía. Pero tan pronto como aparecía una cuestión filosófica estaba lleno de vida» (Stein, 2002: 339).

La timidez de Heidegger, a menudo evocada también por otras personas que lo conocieron, no le impedía ser considerado como un interlocutor válido en «cuestiones filosóficas». Así, sabemos que el 8 de junio de 1918 Edmund Husserl, Edith Stein y Martin Heidegger mantienen un intercambio de ideas relacionadas con la filosofía de la religión. Posiblemente contrastaron entonces sus pareceres sobre las anotaciones póstumas de Adolf Reinach, que van precisamente en esta dirección ${ }^{1}$. En esa fecha ya no era Edith Stein la asistente privada de Husserl, aunque todavía tenía un encargo docente en la Universidad Albert-Ludwig. Y lo mismo que en ella no disminuye el interés personal y humano hacia su maestro Husserl cuando deja de colaborar con él, tampoco dejará de prestar atención a la evolución de Heidegger cuando abandone definitivamente Friburgo. Las cartas de la década de 1920 atestiguan un seguimiento, a distancia, de las esperanzas y logros académicos de Heidegger, así como del afianzamiento de una posición propia en el panorama filosófico. Por ejemplo, en 1926 escribe que Heidegger «discurre por caminos propios» y sabe que no ha publicado nada desde su escrito de habilitación sobre Duns Escoto ${ }^{2}$.

¿Cómo explicar, desde este sentimiento de camaradería, el hecho de que Heidegger se convirtiera, con el tiempo, en el autor más criticado por la filósofa judía? Creemos que las razones de peso no son de índole personal, sino doctrinal.

En el plano de las relaciones personales, Heidegger valoró negativamente el bautismo de Edith Stein en la Iglesia Católica en 1922. Sobre ello manifiesta su opinión a un amigo común, Roman Ingarden, en estos términos: «Lo que usted me escribe sobre la señorita Stein me ha

\footnotetext{
1 Cfr. Carta a Roman Ingarden de 08/06/1918, en Stein, 2001: 85. Hay traducción en español de esas anotaciones en Reinach, 2007.

2 Cfr. Cartas a Roman Ingarden de 09/10/1926 y 24/10/1926, en Stein, 2001: 172 y 173.
} 
entristecido, a mí mismo no me escribió. Es lamentablemente un gran paso en falso, un signo de la miseria interior en las almas. Un auténtico filósofo sólo puede ser libre: la esencia de la filosofía es la autonomía más radical, enteramente según su intención» ${ }^{3}$. Pero no hay indicios de que Edith Stein conociera este juicio de Heidegger. Sí pudo saber, en cambio, que Heidegger, al editar los textos husserlianos sobre fenomenología de la conciencia interna del tiempo (1928) no mencionaba que era ella quien los había ordenado durante su trabajo como asistente privada. Y naturalmente supo que a Heidegger no le gustó el formato de diálogo que había dado a su contribución al volumen de homenaje a Husserl por su jubilación (1929), pues le obligó a redactarlo de nuevo en el estilo más impersonal de una memoria científica. Sin embargo, nada de esto tiene relieve en la correspondencia de Edith Stein.

La discrepancia de Edith Stein con Heidegger es eminentemente de ideas. Se manifiesta de forma clara en la década de 1930, pero creemos que ya la «siente» en la década anterior. Este sentir no expresado es lo que llamamos «hermenéutica blanca» por contraposición a una hermenéutica gris que sería la explícitamente formulada en sus escritos de los años treinta.

Indudablemente Edith Stein precisó su juicio valorativo de la filosofía de Heidegger antes de 1930, y esto se hizo posible desde la lectura de Ser y tiempo. Nuestro propósito es reconstruir en qué podían consistir las contrariedades y complacencias de la antigua colega al leer esta obra emblemática de Heidegger.

\section{La lectura de Ser y tiempo desde tres comentarios azarosos}

En octubre de 1926, Edith Stein sabía que Heidegger estaba preparando una obra sobre Ser y tiempo, pues se mantenía informada sobre el curso del anuario de filosofía dirigido por Husserl. Allí debía publicarse esa obra «que contiene su principal punto de vista», y escribe que Husserl, al examinar los pliegos de imprenta, había acusado las diferencias de los planteamientos de Heidegger respecto de los suyos propios. Esto, en efecto, se puede comprobar también consultando las anotaciones estenográficas que el filósofo hizo a su propio ejemplar de Sery tiempo ${ }^{4}$.

Carta de Heidegger a Roman Ingarden citada en Karger, 1998: 12.

Cfr. Carta a Roman Ingarden de 24/10/1926, en Stein, 2001: 174. Ver también reproducción del ejemplar que usaba Husserl en Sepp, 1988: 335. La obra Ser y tiempo 
Ahora bien, mientras que al comienzo de la década veía con prevención la influencia de Heidegger como una «nueva dirección» que se alejaba de Husserl ${ }^{5}$, ahora alimenta expectativas porque, al parecer, en la obra en ciernes «se trata en lo esencial del dominio de la realidad y de la vida concreta, esto es, de todo aquello que Husserl excluye. Y éste me parece ser el punto hacia el que todo el movimiento filosófico de los últimos años se dirige concentradamente» ${ }^{6}$. Es decir, desde lo que ha oído, interpreta que Heidegger se separa, como ella, de una tendencia idealista en el seno de la fenomenología tal como la que cree hallar en Husserl.

Pero ni esta coincidencia de fondo, ni el interés antropológico compartido con Heidegger evitarán la falta de sintonía con Ser y tiempo. El texto ve la luz a comienzos de 1927 y Edith Stein lo lee ese mismo verano, aunque no entero. Reconoce la alta categoría del escrito que le valió a Heidegger una adscripción estable a la Universidad, pero también arguye que no resulta tan interesante en comparación con lo que tiene entre manos: «Que Heidegger es algo grande y que puede meternos a todos en el bolso, lo creo también a causa de su libro. Antes no lo sabía, o es que veía sólo los efectos, esto es, su gran influjo sobre la generación joven. El libro lo leí en su mayor parte en las vacaciones, pero no lo terminé por completo; concluirlo perdió importancia entre todo lo que desde entonces me presionaba»?

Edith Stein volvió sobre este texto años más tarde, e incluso buscó interpretaciones que complementaran su personal lectura del mismo, como una introducción de Alexander Koyré a la filosofía de Heidegger o la recensión de Sery tiempo que Hedwig Conrad-Martius publicó en 1933. Aquí nos interesa evocar reacciones básicas que pudo suscitar esa primera lectura personal de 1927, la «hermenéutica blanca» que sólo posteriormente se decantó en declaraciones escritas. Lo intentamos desde tres comentarios esporádicos de nuestra autora que, aunque datan de principios de los años treinta, parecen haber conservado esas impresiones primeras y nos las transmiten gracias a su espontaneidad.

apareció publicada en el volumen VIII del famoso anuario Jabrbuch für Philosophie und Phänomenologische Forschung.

5 Cfr. Carta a Roman Ingarden de 15/10/1921, en Stein, 2001: 144: «Nosotros ya hemos discutido mucho qué se podría hacer en contra».

6 Cfr. Carta a Roman Ingarden de 24/10/1926, en Stein, 2001: 174.

7 Cfr. Carta a Roman Ingarden de 02/10/1927, en Stein, 2001: 185. 


\section{1. «Es una obra grandiosa, pero extraña a mí» (enero de 1931)}

Esta es la frase que pronunció Edith Stein ante Max Müller, asistente del profesor Martin Honecker, cuando éste le preguntó su opinión sobre Ser y tiempo a comienzos de 1931. Edith Stein se hallaba de visita en Friburgo, esta vez indagando sobre la disponibilidad de una plaza docente y la oportunidad de preparar un trabajo de habilitación para optar a ella. La obra Ser y tiempo sería, por tanto, un hito filosófico, pero en conjunto extraña o foránea (fremd) a su sensibilidad (Herbstrith, 1990: 206). ¿Cómo se vivió esta extrañeza en la primera lectura? Creemos que cabe conjeturar algunas respuestas.

En primer lugar, desde el modo de proceder de Heidegger. Él quiere hacer una analítica ontológica del Dasein o «ser ahí»—como tradujo José Gaos-, expresión que en todo caso designa al ser humano. Pero en orden a determinar estructuras ontológicas del Dasein comienza analizando los útiles «a la mano»y «ante los ojos». Necesariamente extraño tenía que parecerle a nuestra autora este proceder; ella, que había dedicado su tesis doctoral al tema de la empatía o captación inmediata de las vivencias de los otros. Y aunque Heidegger nota que el «ser ahí» se encuentra a veces ante entes que no tienen la forma de ser de lo «a la mano»y «ante los ojos», sino justamente la del Dasein (vid. \26) ${ }^{8}$, el orden en que trata los problemas puede dar la impresión de que para llegar a las personas hay que comenzar hablando de herramientas.

Esta es una primera «extrañeza» que colisiona con la sensibilidad de Edith Stein hacia todo lo personal. Pero hay otras. Por lo pronto, la deriva hermenéutica que adopta la fenomenología en Ser y tiempo. La importancia que se le da al encontrarse como disposición afectiva que es lugar de desvelamiento del ser, o las extensas consideraciones sobre el comprender, podían resultar extrañas al modo de pensar de Edith Stein.

Ciertamente hay un punto de sintonía entre la lectora y el autor, y es el interés antropológico compartido por ambos. El hecho de que Ser y tiempo en buena medida parezca una obra de antropología - aunque tal calificación requiera matices a la luz de la producción posterior de Heidegger- podría justificar el interés de Edith Stein por su lectura. Tanto más cuanto que Heidegger alude muy pronto (vid. \10) a los constituyentes antropológicos de cuerpo vivo, alma y espíritu según la

\footnotetext{
8 Señalo en el cuerpo del texto los parágrafos de Sery tiempo donde se pueden cotejar algunos de los contenidos que expresamos. Nos guiamos por la edición de Heidegger, 1993. También hacemos alusiones en este artículo a la traducción tradicional de José Gaos (1951) y a la más reciente del chileno Jorge Eduardo Rivera (1997).
} 
tríada de remotas raíces paulinas que tanto protagonismo tiene en el pensamiento de Edith Stein.

No obstante, hay que reparar en que la indagación antropológica de Edith Stein tiene una pretensión paradigmática y normativa, mientras que el análisis de la existencia humana que desarrolla Heidegger se atiene a lo que él llama «cotidianidad del término medio» (durchschnittliche Alltäglichkeit). Es decir, no quiere proponer nada, sino que intenta elaborar solamente una fenomenología de la vida fáctica. De hecho, la tríada arriba mencionada no tiene un papel conductor en los análisis de Heidegger. Además, Edith Stein estaba ya interesándose en 1927 por una concepción diferencial de la antropología que tuviera en cuenta la distinción entre varón y mujer. Frente a ello notamos que el Dasein de Heidegger, pese a encerrar en la denominación misma un matiz de concreción presencial, es asexuado. A veces hasta da la impresión de que carece de cuerpo.

A todo esto hay que añadir algunas divergencias de enfoque en puntos concretos, sean antropológicos o no. Por ejemplo, en la interpretación del vocablo $\lambda \dot{\gamma} \gamma o s$, que para Edith Stein significa «estructura de sentido», lo cual subraya el carácter de conectividad inteligida. Heidegger, en cambio, pone el acento en el carácter de descubierto de algo de lo que se habla, y sólo derivadamente admite el logos como percepción racional (vid. $\int 7$ ).

Por otro lado, es muy posible que Edith Stein se haya dejado interpelar por el concepto de Erschlossenheit (apertura) presente en Ser y tiempo. Es una posición crucial la que ocupa en el pensamiento de nuestra autora el concepto de espíritu como apertura de la persona, y ella misma emplea alguna vez la palabra Erschlossenheit en este contexto. El contraste está en que, a la altura de 1927, Stein sólo reconoce espíritu a las realidades personales. En cambio, la Erschlossenheit de Heidegger -el «estado de abierto» en la traducción de Gaos- es propia no sólo del Dasein, sino del mundo mismo y de los entes. Además, en una primera lectura puede parecer que la apertura del Dasein se da incluso sin un sujeto conocido, que puede ser una apertura asubjetiva (vid. \64: «La cura no ha menester de fundarse en un "sí mismo"»). Por contraste, en los análisis de la persona que lleva a cabo Edith Stein se habla de una espacialidad en que se mueve el yo y que sugiere que éste es verdadero sujeto, hay sujeto de la apertura.

Volviendo a un enfoque panorámico, es razonable suponer una contrariedad que ha podido ser vivida a modo de extrañeza global en la primera lectura de Ser y tiempo por Edith Stein. Esta tiene que ver con el modo de entender la filosofía y el modo de elaborarla. En efecto, la filosofía de Martin Heidegger, ¿no está demasiado condicionada por el 
miedo a incurrir en el «se» (man) y por eso abocada a una suerte de continua arqueología de las palabras? Dicho de otro modo: el constante recurso a las virtualidades etimológicas de vocablos del idioma alemán, ¿no está dictado por el miedo a caer en la dictadura de la publicidad más que por el amor a la verdad? Y en esa medida, ¿no torna inauténtica la filosofía de Heidegger? La formación literaria de Edith Stein no desconoce las etapas de formación de la lengua alemana, sino que, antes bien, incluyó la ocupación con textos góticos y medievales. Pero desde su manera de entender y de escribir la filosofía, necesariamente tenía que parecerle extremado el etimologismo de Heidegger, un rasgo que puede verse como vinculado a la deriva hermenéutica de la fenomenología. A la hermenéutica blanca de Ser y tiempo tenía que hacerle esta obra un efecto «demasiado hermenéutico».

\section{2. «La filosofía de la mala conciencia» (junio de 1931)}

En el verano de 1931 se hallaba Edith Stein en su ciudad natal, Breslau. En una conversación con el profesor de teología Josef Koch, éste recuerda que ella «caracterizó la filosofía de Heidegger como "la filosofía de la mala conciencia"»" ¿Cómo hemos de entender este juicio tan contundente?

En el idioma alemán tiene la expresión scblechtes Gewissen, mala conciencia, el significado de remordimiento por oposición a reines Gewissen, que indica el tener la conciencia limpia. Pero sería demasiado pobre el caracterizar el pensamiento de Heidegger como una filosofía sobre los remordimientos o el sentimiento de culpa. Es cierto que el sentimiento de culpa es tratado en Ser y tiempo. Lo que Heidegger, coincidiendo con Max Scheler, llama allí schlechtes Gewissen, mala conciencia, es un fenómeno derivado de la conciencia vocante. Sin embargo, en un sentido más amplio, mala conciencia significaría conciencia acusadora de una negatividad original. En el curso del análisis de la voz de la conciencia, Heidegger dice que esta voz nos habla de nuestra culpabilidad y deficiencia, de nuestra negatividad radical e insuperable. Algo en lo que José Luis López Aranguren creyó ver puro luteranismo revisitado. La mala conciencia apunta, pues, a la acusación de una negatividad inicial. Desde aquí nos parece que se puede modular una variedad de sentidos por los que la filosofía de Heidegger sería «la filosofía de la mala conciencia».

$9 \quad$ El testimonio está recogido en la primera biografía que se escribió sobre Edith Stein (1948), que ha tenido múltiples ediciones y traducciones. Cfr. Renata de Spiritu Sancto, 1958: 80. 
Por ejemplo, «mala conciencia» podría referirse a la notable cantidad de equívocos que parece contener el texto de Heidegger. Estos resaltan sobre todo en una primera lectura y pueden hacer sospechar de la falta de probidad intelectual del autor en espera de un juicio más contrastado. Así, por ejemplo, aunque en el parágrafo 14 se nos dice que la mundanidad es sólo del Dasein, en el parágrafo 18 parece asignársele al mundo. El parágrafo 44 admite una anterioridad del estar en la verdad sobre el estar en la falsedad, pero luego afirma en el mismo parágrafo - sin justificación al parecer- que el Dasein es con igual originalidad en la verdad y en la falsedad. En general, el tema de la verdad da lugar, a lo largo de varios parágrafos, a priorizar su comprensión como desvelamiento o su comprensión como adecuación, haciendo muy difícil al lector llegar a claridad. La misma oscuridad se advierte en el hábito de definir conceptos sobre la base de otros que luego resultan definidos desde aquellos, recayendo así en metonimias constantes. El curso de la lectura se convierte de este modo en una especie de caza de sombras, como si los conceptos se volvieran espectrales y vacíos, con la misma oquedad que exhiben las esculturas de Eduardo Chillida que Heidegger llegaría a conocer y disfrutar. ¿No será que el filósofo ha querido disimular la confusión bajo la hojarasca gramatical de un estilo verdaderamente enrevesado hasta para alemanes cultos? No podemos descartar este pensamiento en la lectura perentoria, por parte de Edith Stein, de una obra que a muchos ha exigido un año de asidua dedicación. Que el pensamiento de Heidegger sea una «filosofía de la mala conciencia» puede significar que deja un poso de malestar en el lector que trata de sobreponerse críticamente a la autorreferencialidad original descubierta en el discurso.

Además, si se advierte que la acusación de que la filosofía de Heidegger sea «la filosofía de la mala conciencia» es de 1931, no puede referirse solo a Sery tiempo. Presupone, por ejemplo, la lectura de iQué es metafisica?, la lección inaugural de 1929 que le era conocida a Stein. Pero esto no mejora las cosas. Dicho opúsculo y sus prólogo y epílogo posteriores contienen metáforas sobre cuyo rango no es fácil decidir. En otras palabras, no se ve claro por qué ha de preferirse una metáfora a otra en orden a proyectar una línea interpretativa de la filosofía de Heidegger. Si se parte de que el ser sobrenada la nada, como se afirma en ¿Qué es metafísica?, parece que estaría fundado en ella y por tanto que sería razonable el reproche de nihilismo que creyeron justo autores como Alphonse de Waelhens o Augusto Andrés Ortega. Si lo que se acentúa es que la nada es el velo del ser, como se dice en el Post-scriptum a ¿Qué es metafísica? (publicado en Wegmarken, de 1967), entonces puede entenderse la filosofía posterior a Ser y tiempo como un desvelamiento del ser. Esta 
línea interpretativa, más benevolente con Heidegger, ha sido seguida con convicción por su antiguo alumno Johannes Baptist Lotz.

Pero cuando Edith Stein afirma que la filosofía de Heidegger - y ya no sólo Ser y tiempo- es una «filosofía de la mala conciencia» es posible que quiera decir algo que va más allá de la negatividad original ligada a la equivocidad que prodiga el autor. Se trata de que Heidegger, declarando que sólo pretende hacer un análisis fenomenológico de la existencia fáctica, ha asumido de hecho compromisos ontológicos que de ninguna manera eran evidentes. Es decir, ha ido más allá del rendimiento ontológico que cabía esperar de los datos fenoménicos. Por consiguiente, cualquiera que otorgue credibilidad a dicha filosofía acabará probando el fenómeno de la «mala conciencia» una vez que se desengañe de su fidelidad a la verdad y detecte cómo se acusa una mácula original en la misma.

Pongamos un ejemplo. Heidegger ha caracterizado al Dasein como «ser en el mundo», que es la forma de «ser en» que tiene el «ser ahí». Mundo no es el mundo material, sino «aquello "en que" un "ser ahî" fáctico, en cuanto es este "ser ahî", "vive"» (\14). Ahora bien, ¿ंes el «ser en el mundo» un carácter ontológico o solamente óntico, es decir, del «ser ahí» tal como lo conocemos? Heidegger asegura que es un rasgo ontológico. Progresivamente, sin embargo, nos habla de un estado de inhospitalidad (Unheimlichkeit) que se da en el seno de ese «ser en el mundo». Parece que hay como una comezón por la que estamos sin estar. Esta in-quietud creemos que se entendería mejor si fuera sólo óntica y hubiera la posibilidad de un verdadero hogar de reposo para el «ser ahí» aun cuando dejara de ser «ser ahí», ser situado. Pero Heidegger recusa esto último manteniendo, sin embargo, el estatuto ontológico del estar sin acabar de estar.

Pensamos que muchos de los reproches que Edith Stein formulará en los años treinta al pensamiento de Martin Heidegger tienen como base esta denuncia de prejuicios ontológicos. Esta es la que vierte una sospecha sobre las intenciones del autor y la que vertebra la tercera caracterización sumaria de Ser y tiempo que tratamos a continuación.

\section{3. «La teleología inmanente» de la obra de Heidegger (febrero de 1933)}

En una observación pasajera de una carta a su amiga Hedwig Conrad-Martius le invita Edith Stein a leer algunos trabajos suyos porque así, contrastándolos con las filosofías de Nicolai Hartmann y Martin 
Heidegger, «encontraría mucho mejor que yo la teleología inmanente que hay en ellos» $»^{10}$.

Por lo que hace a Heidegger, su obra estaría lastrada de una «teleología inmanente». Es decir, de una intención de fondo que opera como un pie forzado del filosofar. Esta es precisamente la crítica que nuestra autora había hecho a algunos otros filósofos que conoció, como el neokantiano Leonard Nelson. Pero, ¿en qué puede consistir esa teleología inmanente en el caso de Sery tiempo?

Creemos que en el ánimo de la autora judía el mayor prejuicio que cree encontrar en Heidegger como lesión de los datos fenoménicos es la reducción de todo a algo temporal y finito. La insistencia con que acusa al filósofo suabo de haber situado al ser, y al «ser ahí», en el único horizonte de lo temporal finito parece indicar que esta presunción ya cobró cuerpo en la primera lectura que hizo de Ser y tiempo. Y que ya entonces, en el año 1927, creyó que la obra estaba conducida por esta teleología inmanente.

Es muy posible que el buen conocedor de Heidegger se vea en la obligación de corregir apreciaciones que Edith Stein ha expresado sobre Ser y tiempo. Pero también es cierto que una primera lectura, e incompleta, podía dar pie a este malestar ante la irrevocable finitud del «ser ahí». El mundo no es el conjunto de los entes, pero no hay más mundo que el ónticamente vivenciado. El estar arrojado - la Geworfenheit- no es una degradada condición abyecta, sino principalmente entrega a la responsabilidad de la propia existencia; sin embargo, es cierto que alguna vez se habla de estar arrojado en el mundo con un significado de mundo que parece el óntico vulgar (vid. \45). En el estar arrojado -el «estado de yecto» de José Gaos- hay así una valoración ontológica de degradación y caída. La temporalidad, en fin, no es lo que vulgarmente entendemos por tiempo. Con buen criterio, a nuestro parecer, ha traducido Jorge Eduardo Rivera como temporeidad la palabra alemana Zeitlichkeit para alejarla del lenguaje cotidiano. Pero no son pocas las indicaciones de Heidegger que hacen pensar que la facticidad del Dasein se resuelve en finitud y caducidad temporal. El mismo vocablo Zeitlichkeit es entendido por cualquier persona natural de Alemania como una palabra del lenguaje ordinario que significa simplemente temporalidad.

El ser del «ser ahí» es lo que Heidegger llama Sorge, palabra que Gaos tradujo como cura y Rivera como cuidado. No es momento de decidir sobre la traducción más idónea, que está también condicionada por las resonancias semánticas que puede tener una misma palabra del idioma español en los países que lo comparten. Lo cierto es que la definición de

10 Carta a Hedwig Conrad-Martius de 24/02/1933, en Stein, 2000: 265. 
la Sorge comporta una estructura compleja en la que ya se anuncia el sello de la temporalidad. La cura o cuidado es «pre-ser-se-ya-en (el mundo) como ser-cabe (los entes que hacen frente dentro del mundo)». Es patente la preformación de las dimensiones temporales - futuro, pasado y presente- en esta definición, así como en uno de los modos originales del Dasein, cual es la vocación de la conciencia. Heidegger define esta vocación de la conciencia como un llamar hacia adelante hacia lo que uno ya era sorteando el estado de caída. O, como dice en filigrana idiomática, vorrufender Rückruf (llamada hacia atrás que llama hacia adelante). Extensos análisis conducen a exponer desde el parágrafo 61 cómo, finalmente, la temporalidad (o temporeidad en la traducción chilena) es el sentido ontológico de la Sorge, por tanto del ser del Dasein. Si esto justifica el interpretar que en último término esa temporalidad se disuelve en tiempo en el caso del hombre, esta parece haber sido la percepción de Edith Stein. Otros matizarán que el tiempo sólo afecta a la comprensión del ser. Así, Emmanuel Levinas, que en Totalidad e infinito escribe lo siguiente: «Sein und Zeit no ha sostenido, tal vez, más que una sola tesis: el ser es inseparable de la comprensión del ser (que se desarrolla como tiempo), el ser es ya apelación a la subjetividad» (Levinas, 1961: 15).

Pero la primera hermenéutica de nuestra autora en relación con la temporalidad del Dasein, acertada o no, de nuevo podía encontrar fundamento en varias observaciones acerca de la muerte. Que el «ser en el mundo» sea un «ser para la muerte» no tiene nada de objetable desde el punto de vista fáctico, aun cuando es cuestionable que sea evidente respecto de uno mismo (nadie ha observado su propia muerte). Pero que esa muerte sea un final irrebasable, esto es una suposición gratuita si se recuerda que - desde la definición de mundo- «ser en el mundo» no tenía que identificarse con «ser en este mundo». A pesar de ello, dicha suposición es la que parece asumir Heidegger cuando escribe sobre la irreferibilidad (Unbezüglichkeit) de la muerte (vid. \62). Una expresión que pudiera parecer que prejuzga contra la relación con toda posible trascendencia (si bien esta tesis parecería justificada en tanto nos mantengamos inamovibles en los límites del «ser ahí»).

La fundamentación del «ser ahí» en la temporalidad, y con ello la propia finitud del ser que en él se manifiesta, es la idea que parece haber guiado teleológicamente el análisis de Heidegger según la interpretación de Edith Stein. Por eso ella expresará a menudo, cuando haga la hermenéutica gris de su obra, que esta ha sido su precomprensión: «De antemano todo está dispuesto para demostrar la temporalidad del ser. 
Por dondequiera que se encuentre una perspectiva de lo eterno, se pone un cerrojo» (Stein, 1950: 134, nota) ${ }^{11}$.

La finitud temporal del ser y del «ser ahí» como prejuicio teleológico de Ser y tiempo, expresado ya en las primeras páginas, no podía pasar sin crítica a alguien que estaba imbuyéndose en el pensamiento cristiano de la mano de santo Tomás de Aquino. En 1933 ya había publicado Edith Stein sus dos volúmenes de traducción de las Quaestiones disputatae de veritate, texto del que se venía ocupando al menos desde 1925. En una perspectiva tomista, en la medida en que conocemos atemáticamente el ser bajo las especies del ente, por tanto bajo la condición de la puesta en duración (la Zeitigung de Heidegger) propia de lo sensible, el tiempo será tanto manifestación como ocultación del ser. Hay una intemporalidad última del ser. Esto se ve también cuando se considera el ente como un trascendental, que como tal englobaría a Dios mismo y por eso sería intemporal. Edith Stein había visto esto al traducir la cuestión primera, artículo primero, de las cuestiones De veritate. Por eso el mismo Tomás dice en un pasaje del De natura generis que Dios está por encima de todo ente. Es decir, el ente, en su significación trascendental, lleva ya la marca de su origen no trascendental. Como dice Johannes Baptist Lotz: «el tiempo se presenta como el horizonte que de comienzo hace mediatamente posible la cosecha del ser, pero que finalmente, en virtud de la especificidad del ser en su cosecha, lleva necesariamente más allá de él mismo y obra sobre la eternidad el horizonte que le funda. Así, "Tiempo y ser" (otra manera de designar la filosofía de Heidegger posterior a Ser y tiempo según Lotz) se cumple en "Ser y eternidad", estando la segunda díada actuando siempre dentro de la primera; y es el propio Heidegger el que nos conduce más allá de Heidegger» (Lotz, 1988: 84).

\section{A modo de balance}

Las reacciones de contrariedad de Edith Stein que hemos tratado de reconstruir como una primera recepción de Ser y tiempo no deben hacernos olvidar que esta obra es justipreciada por la autora judía y que la belleza de algunas intuiciones de Heidegger pudo no pasarle desapercibida. Más aún, suscitan una pregunta legítima por la posibilidad de que Ser y tiempo haya influido en algún aspecto de su pensamiento. O al menos en el curso del mismo. En 1927 estaba ella confrontándose con las Quaestiones disputatae de veritate de Sto. Tomás y tal vez no tenía una 11 Los editores de las Edith Stein Gesamtausgabe, vol. 11/12 han cambiado la ubicación
de este texto. 
conciencia tan acusada de la idiosincrasia de la ontología tomista. Aunque creemos que sí la suficiente como para no admitir que una ontología fundamental haya de consistir en una analítica del Dasein, tal como pretende Heidegger. Lo cierto es que la lectura de Ser y tiempo ha condicionado algo de su propia marcha intelectual. No hemos de olvidar el título y el subtítulo de la obra más voluminosa de Edith Stein, que estaba fundamentalmente acabada en 1936. La obra iba a titularse Ser eterno y ser finito. Una mirada de través por la philosophia perennis. Este es el título y subtítulo que aparecen tachados en el manuscrito, encabezando el índice. Edith Stein desestimó esto y antepuso una hoja a todo el manuscrito con el siguiente título: Ser finito y ser eterno. Tentativa de una ascensión al sentido del ser. El detalle no es indiferente. El primer título es tomista y trae un subtítulo que puede recordar la negación de la posibilidad de una filosofía cristiana por Heidegger, en su Introducción a la metafísica, y la discusión que tuvo lugar al respecto en París, en 1931. El segundo título trastoca el orden entre lo eterno y lo finito - lo que sugiere que tiene más presente la perspectiva moderna y heideggeriana-, mientras que el subtítulo tiene claramente como trasfondo la confrontación con Ser y tiempo. El sentido del ser o su verdad es lo que Heidegger trataba de desvelar, bien que por un camino harto diferente, en aquella obra. Y creemos honestamente que no ha de descartarse que algún punto doctrinal de la autora haya recibido un impulso desde Ser y tiempo.

Los estudios sobre la relación entre Edith Stein y Martin Heidegger suelen tomar como base los escritos de esa etapa de madurez en que la autora ya se expresa libremente en una «hermenéutica gris» de la filosofía de Heidegger, a saber: «El significado de la fenomenología como visión del mundo» (fechado en 1932 por los editores), Potencia y acto (1932), La estructura de la persona bumana (1932), Ser finito y ser eterno (1936) y, especialmente, el apéndice a esta última obra titulado «La filosofía existencial de Martin Heidegger». Todos ellos son de los años treinta. Una lectura serena del libro de Heidegger, Ser y tiempo, suscita legítimamente la pregunta de hasta qué punto Edith Stein habría sido capaz, en un primer contacto con el texto, de ubicarse en el plano en que se sitúa el discurso de este autor. Creemos que es posible sostener la temporalidad del Dasein sin indicar, en principio, nada en contra de una «vida después de la muerte». Pues dicha temporalidad sólo afecta al ser situado, al «ser ahí». Naturalmente que el Dasein deja de ser, con la muerte, posibilidad abierta, deja de ser Dasein. Algunas exposiciones actuales de la filosofia de Heidegger no manifiestan desazón ante la tesis de la finitud del Dasein y aceptan pacíficamente que es ante la muerte 
como éste puede comprenderse como total o entero ${ }^{12}$. En cualquier caso, muy pronto hay declaraciones de Edith Stein que conjuran una interpretación unilateral - por ejemplo de tipo nihilista- de Ser y tiempo. En el escrito «El significado de la fenomenología como visión del mundo» advierte lo siguiente: «En el estado actual me parece prematuro indicar respecto a Heidegger su imagen del mundo. La posición central del ser ahí, el relieve dado a la cura como esencialmente perteneciente a él, a la muerte y a la nada, así como algunas formulaciones extremas, muestran una imagen del mundo como sin Dios, antes bien, claramente nihilista. Pero hay también aserciones que dejan aparecer la posibilidad de un vuelco, de manera que el ser abi, en sí mismo nulo, encuentre su apoyo en un fundamento absoluto de ser» (Stein, 1962: 14).

La propia Edith Stein ha buscado compensar la perspectiva de Heidegger con la afirmación de la eternidad y no solo de la temporalidad. Este pensamiento de raigambre cristiana y tomista lo desarrolla en un análisis de la sucesión y la simultaneidad en la conciencia del «yo soy», en Ser finito y ser eterno. Con lo cual muestra con un proceder fenomenológico el pensamiento que había expresado Tomás de Aquino de la presencia del simul en la sucesión. La eternidad se manifiesta de alguna manera en el tiempo, algo que para algunos lectores de Heidegger no estaría en modo alguno excluido de sus planteamientos.

Hemos podido comprobar que Edith Stein usa a veces en su hermenéutica gris sobre la obra y el pensamiento de Heidegger una actitud de cautela. Aquí hemos ensayado brevemente una lectura de Sery tiempo con los ojos con que Edith Stein podía mirar esa obra leída, de manera incompleta, en el verano de 1927. Ella entendió que algunas aserciones de Heidegger sobrepasaban un análisis imparcial, tal como declarará reiteradamente más tarde. Y hay otros aspectos muy concretos que harían fruncir el ceño a la discípula de Husserl: la identificación de la fenomenología con una ontología ya al comienzo del libro (vid. \7), la explicación de la empatía como un caso de inferencia por analogía (vid. \$ 26) — cosa que ella había combatido en su tesis doctoral-, la centralidad misma del término Sorge -que, aunque con un significado diferente, había suscitado su rechazo en lo que parece ser el primer escrito posterior a su conversión ${ }^{13}$-, etc. Pero creemos que los tres comentarios

12 Cfr., por ejemplo, Vattimo, 1986 y Rodríguez García, 1987. Escribe Arturo Leyte: "Final" no significa acabamiento, sino también comienzo, porque "fin" sólo significa límite. Sólo la concepción vulgar del tiempo hace coincidir final y término» (Leyte, 2005: 148-149).

13 Dicho escrito es el que los editores titularon Die ontische Struktur der Person (La estructura óntica de la persona). Se halla publicado en Stein, 1962: 137-197. Actualmente hay cierto acuerdo entre los especialistas en considerar que el escrito 
fugaces que nos han llegado por boca de testigos y de unas líneas epistolares de la autora dan pie para recrear las líneas directrices de su hermenéutica blanca de Ser y tiempo.

\section{REFERENCIAS}

-Heidegger, M. (1993). Sein und Zeit. Tubinga: Max Niemeyer.

-Heidegger, M. (1971). El ser y el tiempo. (J. Gaos, Trad.). Madrid: Fondo de Cultura Económica.

-Heidegger, M. (1997). Ser y tiempo. (J. E. Rivera, Trad.). Santiago de Chile: Editorial Universitaria.

-Herbstrith, W. (Ed.). (1990). Erinnere dich - vergiß es nicht. Edith Stein christlichjüdische Perspektiven. Annweiler: Plögger Verlag.

-Karger, M. (1998). Ein Zeugnis für die Versöhnung von Juden und Christen. Deutsche Tagepost (123), Oktober.

-Levinas, E. (1961). Totalité et infini. Essai sur l'extériorité. La Haya: Martinus Nijhoff.

-Leyte, A. (2005). Heidegger. Madrid: Alianza Editorial.

-Lotz, J. B. (1988). Martin Heidegger et Thomas d'Aquin. (Ph. Secretan, Trad.). Paris: Presses Universitaires de France.

-Reinach, A. (2007): Anotaciones sobre filosofía de la religión. (J. L. Caballero Bono, Trad.). Madrid: Ediciones Encuentro.

-Renata de Spiritu Sancto, T. (1958). Edith Stein. Eine große Frau unseres Jabrbunderts. Friburgo de Brisgovia: Herder.

-Rodríguez García, R. (1987). Heidegger y la crisis de la época moderna. Madrid: Cincel.

-Sepp, H.-R. (Ed.). (1988). Edmund Husserl und die Pbänomenologische Bewegung. Zeugnisse in Text und Bild. Friburgo/Munich: Karl Alber.

-Stein, E. (1950). Endliches und ewiges Sein. Versuch eines Aufstiegs zum Sinn des Seins. (Edith Steins Werke, Vol. II). Lovaina/Friburgo de Brisgovia: E. Nauwelaerts/Herder.

-Stein, E. (1962). Die weltanschauliche Bedeutung der Phänomenologie. Welt und Person. Beitrag zum Christlichen Wabrheitsstreben. (Edith Steins Werke, Vol. VI). Lovaina/Friburgo de Brisgovia: E. Nauwelaerts/Herder.

-Stein, E. (2000). Selbstbildnis in Briefen I. (Edith Stein Gesamtausgabe, Vol. 2). Friburgo de Brisgovia: Herder.

-Stein, E. (2001). Selbstbildnis in Briefen III. Briefe an Roman Ingarden. (Edith Stein Gesamtausgabe, Vol. 4). Friburgo de Brisgovia: Herder.

debería titularse más bien Freibeit und Gnade (Libertad y gracia), de acuerdo con el índice del mismo elaborado por la autora. La presencia del concepto Sorge en el texto hizo pensar por un tiempo que su redacción sería posterior a Sery tiempo. 
-Stein, E. (2002). Aus dem Leben einer jüdischen Familie und weitere autobiographische Beiträge. (Edith Stein Gesamtausgabe, Vol. 1). Friburgo de Brisgovia: Herder.

-Vattimo, G. (1986). Introducción a Heidegger. Barcelona: Gedisa.

Sumario: 1. Contexto de la relación con Heidegger; 2. La lectura de Ser y Tiempo desde tres comentarios azarosos; 2.1. «Es una obra grandiosa, pero extraña a mí» (enero de 1931); 2.2. «La filosofía de la mala conciencia» (junio de 1931); 2.3. «La teleología inmanente» de la obra de Heidegger (febrero de 1933); 3. A modo de balance; Referencias. 